\title{
Arousability in sleep apnoea/hypopnoea syndrome patients
}

\author{
K. Dingli*, I. Fietze ${ }^{\#}$, T. Assimakopoulos ${ }^{\star}$, S. Quispe-Bravo*, C. Witt\#, N.J. Douglas*
}

\begin{abstract}
Arousability in sleep apnoealhypopnoea syndrome patients. K. Dingli, I. Fietze, T. Assimakopoulos, S. Quispe-Bravo, C. Witt, N.J. Douglas. (C) ERS Journals Ltd 2002. ABSTRACT: Sleep disruption and daytime sleepiness in obstructive sleep apnoea/ hypopnoea syndrome (OSAHS) patients result from recurrent apnoeas/hypopnoeas and arousals from sleep. Around $30 \%$ of apnoeas/hypopnoeas are not terminated by visible cortical arousals. The current authors tested the hypotheses that arousal induction is linked to sleep stage, oxygen desaturation, event type, event duration and time of occurrence during the night.

Fifteen patients with OSAHS of varying severity were studied and all their apnoeas/ hypopnoeas were evaluated.

Eight of 15 patients had apnoeas/hypopnoeas in all sleep stages, and all their 610 apnoeas/hypopnoeas were analysed in the between stages comparison; data from all 15 patients were included in other comparisons. Thirty-four per cent of apnoeas/ hypopnoeas during slow wave sleep (SWS) were associated with arousal, significantly less than the $77 \%$ during nonrapid eye movement (NREM) 1 and 2 and $62 \%$ during rapid eye movement (REM) sleep. Arousal induction was not affected by oxygen desaturation, event type, duration or time of the night. The apnoea/hypopnoea index was $39 \cdot h^{-1}$ in NREM 1 and 2 , significantly higher compared to $17 \cdot h^{-1}$ in REM or to $11 \cdot h^{-1}$ in SWS sleep.

In conclusion, apnoeas/hypopnoeas in slow wave sleep are associated with fewer cortically apparent, visually detected arousals.
\end{abstract}

Eur Respir J 2002; 20: 733-740.

\author{
*Respiratory Medicine Unit, Univer- \\ sity of Edinburgh, UK. " Respiratory \\ Medicine, Charite, Berlin, Germany. \\ Dynesys Ltd, Edinburgh, UK. \\ Correspondence: N.J. Douglas \\ Dept of Medicine \\ Royal Infirmary \\ Edinburgh EH3 9YW \\ UK \\ Fax: 441315363255 \\ E-mail: n.j.douglas@ed.ac.uk
}

\author{
Keywords: Arousal \\ sleep apnoea \\ sleep stage
}

Received: July 192001

Accepted after revision: April 112002

K. Dingli was supported by a Research Fellowship from the European Respiratory Society.
Obstructive sleep apnoea/hypopnoea syndrome (OSAHS) affects $1-4 \%$ of the population [1] and is more common among middle-aged men. The major symptom is daytime sleepiness, a risk factor for accidents [2, 3], which impairs quality of life and creates difficulties and embarrassing situations at work and in the social environment. Previous studies of the factors causing sleepiness in OSAHS patients, have found weak correlations between polysomnographic findings and both objective and subjective measurements of daytime sleepiness $[4,5]$. In part, this may be because the recurrent arousals, which modelling studies have shown are central to daytime dysfunction [6, 7], are poorly identified [8]. Not all apnoeas/hypopnoeas are terminated by visible cortical arousals, which are absent in about $30 \%$ of them [9].

However, there may be differences between events which predispose to more marked arousal reactions. These might include event duration and severity of oxygen desaturation. Furthermore, there may be differences between sleep stages in arousability or in the visibility of arousals.

The current authors have therefore investigated the hypotheses that arousability varies between light sleep (nonrapid eye movement (NREM) 1 and 2), slow wave sleep (SWS) and rapid eye movement sleep (REM), and that visible cortical arousals are more common with longer apnoeas/hypopnoeas and with more severe desaturation. The study also aimed to examine the effects of respiratory event type, apnoeas or hypopnoeas, and the time of their occurrence during the night on cortical responses.

\section{Methods}

\section{Subjects}

Fifteen patients (14 male, age 51 (SD 9) yrs, body mass index 29 (SD 2) $\mathrm{kg} \cdot \mathrm{m}^{-2}$ ) with excessive daytime sleepiness and at least one further OSAHS symptom [10], underwent diagnostic polysomnography. Patients with periodic limb movement disorder, other neurological, cardiac or pulmonary diseases, or intake of medication which affected sleep, were excluded. The study was approved by the Institutional Ethics Committee.

\section{Polysomnography}

Polysomnography was performed using a computerised recording system consisting of: 1) two central (C3A2, C4A1) and two occipital (O1A2, O2A1) electroencephalogram (EEG) tracings, two outer canthi electrodes (LEOG, REOG) and a submental electromyogram (EMG) electrode; 2) tibial EMG; 3) three-lead electrocardiogram; 4) oronasal airflow 
detection by a thermistor sensor, thoracoabdominal movement detection by two piezoelectric belts, a digital microphone and a pulse oximeter.

Recordings were carried out between 22:00 and 07:00 h. They did not include continuous recording of supine body position.

\section{Scoring, definitions}

Scoring was performed by a single observer, blinded to subject. Sleep and arousals were scored from the C4A1 and C3A2 tracings. Sleep was scored according to the criteria proposed by RECHTSCHAFFEN and KALES [11]. An arousal was scored when an abrupt shift to a faster EEG frequency (including theta, alpha and/or greater frequencies but no spindles) occurred and lasted $1-15 \mathrm{~s}$, i.e. arousal scoring was based on the definition of the American Sleep Disorders Association (ASDA), modified to the time threshold which was set at $1 \mathrm{~s}$ rather than $3 \mathrm{~s}$ [12]. Arousals with no preceding apnoeas/hypopnoeas were defined as spontaneous arousals. Arousals overlapping or adjacent to apnoeas/hypopnoeas were defined as respiratory arousals. Arousal scoring ranged from 1-15 s, irrespective of sleep recurrence or prolonged awakening subsequent to the arousal; hence, the awakenings as
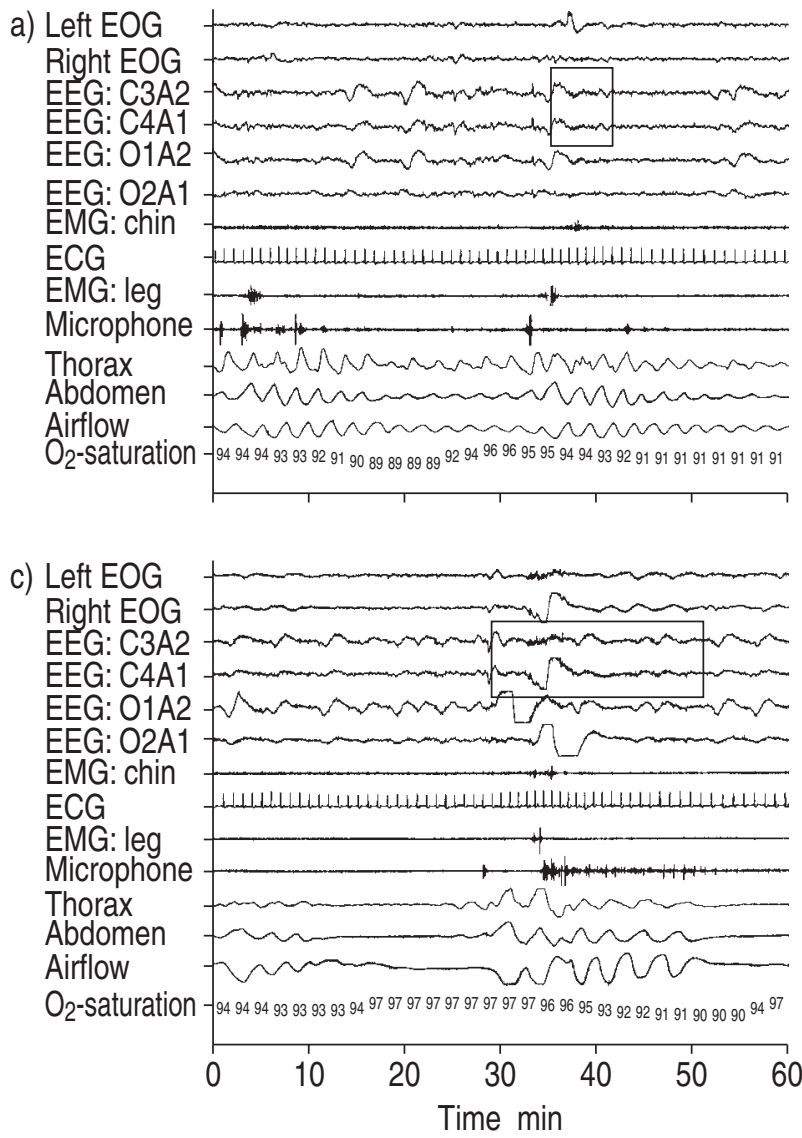

described by RECHTSCHAFFEN and KALES [11] were also included in the scoring.

The numbers of each arousal type per hour of sleep were termed the spontaneous arousal index (SAI) and the respiratory arousal index (RAI). Respiratoryarousals were categorised according to the following: 1) 1-3 s of duration, 2) 3-15 s of duration, or 3) RECHTSCHAFFEN and KALES [11] awakenings $>15 \mathrm{~s}$. The respiratory events which were not terminated by cortical arousals were categorised into events causing: 1) no EEG changes, or 2) lightening in sleep stage in the epoch following the event termination (e.g. from stage 3 to 2) (fig. 1).

Apnoeas were defined as cessation of the oronasal airflow, lasting $\geqslant 10$ s. Hypopnoeas were defined as airflow reduction of $>50 \%$, compared to a 10 s peak amplitude during the preceding $2 \mathrm{~min}$, lasting $\geqslant 10 \mathrm{sec}$ and associated with either oxygen desaturation of $\geqslant 3 \%$ or an arousal [13].

Arousals and respiratory events were scored separately during two sessions.

Oxygen saturation was based on a second-bysecond measurement within a window set from the beginning of each event until the middle of the following and/or a maximum of $120 \mathrm{~s}$.

Apnoea/hypopnoea index (AHI) and arousal indices were calculated for each sleep state.
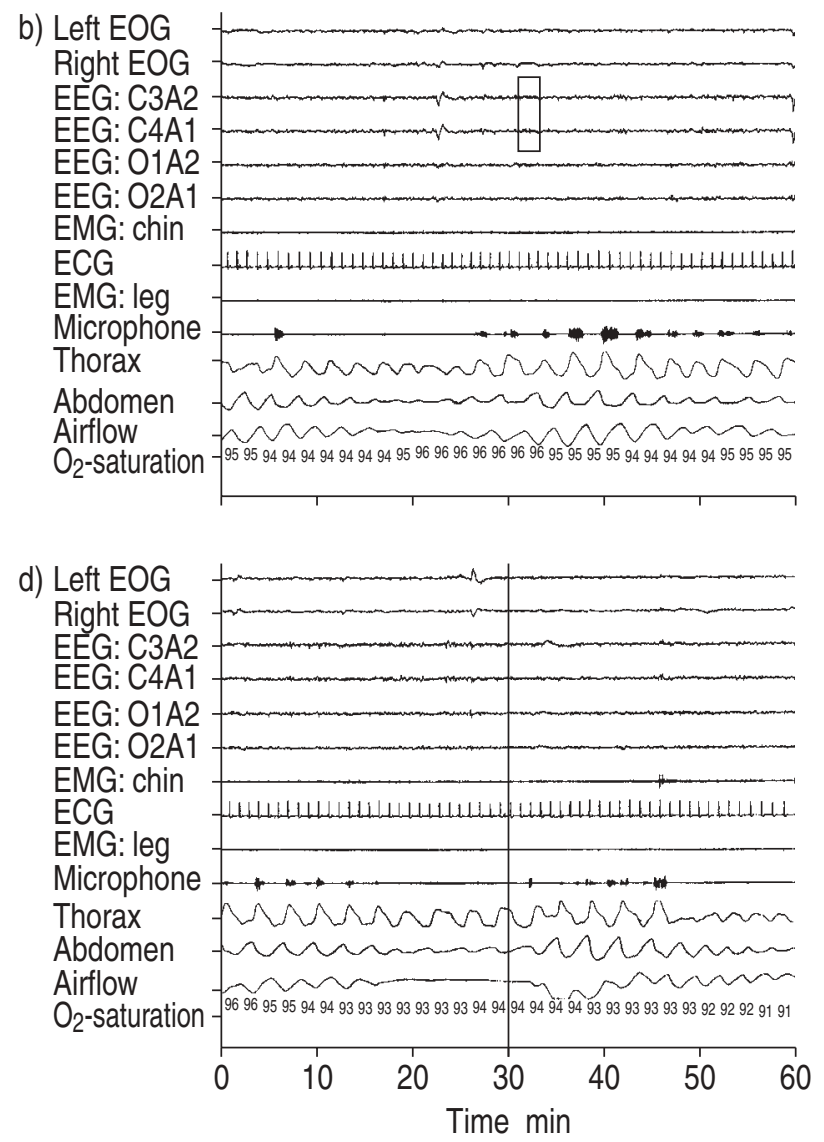

Fig. 1.-Four examples of scoring: a) hypopnoea inducing a 5-s arousal; b) hypopnoea inducing a 2-s arousal; c) apnoea causing awakening; and d) apnoea that begins in rapid eye movement (REM)-sleep and self-terminates in the following epoch, causing a transition from REM to stage 1 (lightening). EOG: electrooculogram; EEG: electroencephalogram (tracings: C3A2, C4A1, O1A2 and O2A1); EMG: electromyogram; ECG: electrocardiogram; $\mathrm{O}_{2}$ : oxygen. 
Table 1.-Intrarater variability for sleep states, sleep efficiency, apnoea-hypopnoea index $(\mathrm{AHI})$ and arousal index (Arl) in 15 patients

\begin{tabular}{ll}
\hline & Intrarater variability \\
\hline Sleep efficiency & $0.8 \pm 0.5$ \\
NREM 1 and 2 sleep & $0.5 \pm 0.2$ \\
SWS & $0.2 \pm 0.09$ \\
REM sleep & $0.4 \pm 0.2$ \\
AHI $1 \cdot h^{-1}$ & $1.7 \pm 0.9$ \\
ArI $1 \cdot h^{-1}$ & $3.0 \pm 0.4$ \\
\hline
\end{tabular}

Data are presented as mean difference \pm SEM in $\%$ of the highest score. NREM: nonrapid eye movement; SWS: slow wave sleep; REM: rapid eye movement.

To assess the accuracy and reproducibility of scoring outcomes, the polysomnograms from the 15 patients were scored twice by the same researcher. In these intrarater analyses the researcher was blind to the patient details and the results of the comparison studies. Intrarater comparisons were made 12 months after the initial study was scored. Variability was calculated as the difference between the two scores in per cent. Across the patients the highest variability between scores was 3\% for arousal index, but $94 \%$ of these scores differed by $<3$ arousals $\cdot \mathrm{h}^{-1}$ (table 1 ).

The influence of the following factors on the induction of respiratory arousals were then investigated: 1) sleep state during which the respiratory event occurred, 2) event type (apnoea versus hypopnoea), 3) event duration, 4) oxygen desaturation, and 5) time of night.

\section{Statistical analysis}

Analysis of variance (ANOVA) was performed for the detection of sleep state-related differences in AHI, RAI and SAI, across the patients. Post-hoc analysis was performed with the least-significant difference test for pairwise multiple comparisons.

ANOVA was performed to detect changes in the induction of respiratory arousals due to the time of the night. Paired comparisons between the RAI before and after $02: 30 \mathrm{~h}$ during NREM 1 and 2 were performed to further assess changes in arousal threshold.

The Chi-squared test was performed to assess significant association between respiratory event type and arousal induction. Paired t-tests were performed to evaluate the significance of event duration and oxygen desaturation on the arousal induction.

Tests were two-tailed and $\mathrm{p}<0.05$ was accepted as statistically significant. The data are presented as the standard error of the means (SEM) or the interquartile range (IQR).

\section{Results}

\section{Sleep architecture}

All patients showed a disturbed sleep pattern. Mean sleep efficiency was $87.6 \pm 3.5 \%$ of the sleep period

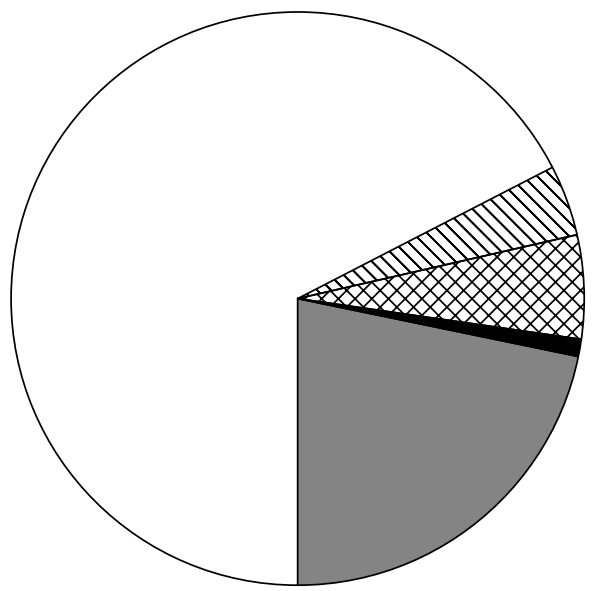

Fig. 2.-Of all apnoeas/hypopnoeas 67.4\% caused American Sleep Disorders Association arousals ( $\square$ ), 4.0\% caused 1-3-s arousals $(\mathbb{\nabla}), 5.9 \%$ caused awakenings described by RECHTSCHAFFEN and KALES (11] ( $22.0 \%$ were terminated without any visible electroencephalographic change $(\square)$ and $0.7 \%$ ( $\boldsymbol{\square})$ caused sleep lightening during the epoch that followed the event termination.

time. Mean time spent in NREM 1 and 2 was $64.4 \pm$ $3.6 \%$, in SWS $21.2 \pm 2.4 \%$, and in REM $14.3 \pm 2.2 \%$ of the total sleep time.

\section{Apnoeas/hypopnoeas and cortical arousals}

Across the 15 polysomnograms, 2,667 apnoeas/ hypopnoeas and 2,056 respiratory arousals were scored (fig. 2). There were 2,326 apnoeas/hypopnoeas during NREM 1 and 2, 128 during SWS and 213 during REM sleep. There were 1,900 respiratory arousals during NREM 1 and 2, 31 during SWS and 125 during REM sleep.

The mean AHI of the 15 patients was $31 \cdot \mathrm{h}^{-1}$ (range $10-75 \cdot \mathrm{h}^{-1}$ ). The mean arousal-index was $34 \cdot \mathrm{h}^{-1}$ (range $\left.16-70 \cdot \mathrm{h}^{-1}\right)$. The mean SAI was $10 \cdot \mathrm{h}^{-1}\left(\right.$ range $\left.4-25 \cdot \mathrm{h}^{-1}\right)$ and mean RAI was $24 \cdot \mathrm{h}^{-1}$ (range $8-52 \cdot \mathrm{h}^{-1}$ ). Eighty per cent of the respiratory events caused visible cortical arousals, 20\% did not (table 2, individual data table 3).

Table 2.-Apnoea-hypopnoea index (AHI) and arousal indices in different sleep stages

\begin{tabular}{|c|c|c|c|c|}
\hline & $\underset{\text { night }}{\text { All }}$ & $\begin{array}{l}\text { NREM } 1 \\
\text { and } 2\end{array}$ & REM & SWS \\
\hline $\mathrm{AHI} \mathrm{h}^{-1}$ & $30.5 \pm 4.5$ & $\begin{array}{l}39.6 \pm 4.5 \\
38.1+4.9^{\#}\end{array}$ & $\begin{array}{l}16.8 \pm 4.1 \\
20.8+5.4^{\#}\end{array}$ & $\begin{array}{l}11.5 \pm 4.9 \\
14.9+6.8^{\#}\end{array}$ \\
\hline RAI h ${ }^{-1}$ & $23.4 \pm 3.3$ & $29.6 \pm 4.8^{\#}$ & $11.8 \pm 2.4^{\#}$ & $5.1 \pm 3.3^{\#}$ \\
\hline SAI $^{-1}$ & $10.4 \pm 1.3$ & $13.8 \pm 1.8$ & $\begin{array}{r}5.4 \pm 0.6\end{array}$ & $\begin{array}{r}4.9 \pm 1.0 \\
4.9 \pm 0\end{array}$ \\
\hline
\end{tabular}

Data are presented as mean \pm SEM. NREM: nonrapid eye movement; REM: rapid eye movement; SWS: slow wave sleep; RAI: respiratory arousal index; RE: respiratory events; SAI: spontaneous arousal index. Results apply to $\mathrm{n}=15$ patients. ${ }^{\#}: \mathrm{n}=8$ patients in whom apnoeas/hypopnoeas occurred in all sleep stages. 
Table 3. - Individual apnoea/hypopnoea index (AHI) and arousal indices in each sleep stage

\begin{tabular}{|c|c|c|c|c|c|}
\hline Patient no. & Time $\mathrm{h}$ & AHI $h^{-1}$ & $\mathrm{RAI} \mathrm{h}^{-1}$ & Ratio \% of all RE & $\mathrm{SAI} \mathrm{h}^{-1}$ \\
\hline \multicolumn{6}{|l|}{1} \\
\hline NREM 1 and 2 & 4.4 & 38.7 & 37.6 & 97 & 13.0 \\
\hline REM & 1.1 & 5.3 & 5.3 & 100 & 4.4 \\
\hline SWS & 1.5 & 1.9 & 1.3 & 66 & 2.6 \\
\hline \multicolumn{6}{|l|}{$2^{\#}$} \\
\hline NREM 1 and 2 & 2.8 & 79.6 & 58.8 & 74 & 19.0 \\
\hline REM & 0.02 & 0.0 & 0.0 & 0 & 50.0 \\
\hline SWS & 0.6 & 52.6 & 21.0 & 40 & 10.5 \\
\hline \multicolumn{6}{|l|}{$3^{\#}$} \\
\hline NREM 1 and 2 & 3.7 & 57.8 & 42.4 & 73 & 34.5 \\
\hline REM & 0.3 & 41.4 & 37.9 & 91 & 3.5 \\
\hline SWS & 0.7 & 0.0 & 0.0 & 0 & 11.7 \\
\hline \multicolumn{6}{|l|}{$4^{\#}$} \\
\hline NREM 1 and 2 & 3.8 & 18.1 & 15.2 & 84 & 10.5 \\
\hline REM & 0.8 & 0.0 & 0.0 & 0 & 8.6 \\
\hline SWS & 2.2 & 0.9 & 0.0 & 0 & 3.2 \\
\hline \multicolumn{6}{|l|}{$5^{\#}$} \\
\hline NREM 1 and 2 & 2.7 & 18.7 & 17.5 & 94 & 15.3 \\
\hline REM & 0.9 & 5.4 & 4.3 & 80 & 4.3 \\
\hline SWS & 1.8 & 0.0 & 0.0 & 0 & 1.8 \\
\hline \multicolumn{6}{|l|}{6} \\
\hline NREM 1 and 2 & 4.5 & 18.5 & 12.5 & 67 & 8.0 \\
\hline REM & 0.5 & 14.9 & 10.6 & 71 & 8.5 \\
\hline SWS & 1.5 & 15.6 & 2.0 & 13 & 2.0 \\
\hline \multicolumn{6}{|l|}{7} \\
\hline NREM 1 and 2 & 4.1 & 51.8 & 44.8 & 87 & 4.3 \\
\hline REM & 0.9 & 43.7 & 20.7 & 47 & 2.3 \\
\hline SWS & 1.6 & 2.5 & 1.4 & 50 & 3.2 \\
\hline \multicolumn{6}{|l|}{$8^{\#}$} \\
\hline NREM 1 and 2 & 4.8 & 37.1 & 35.9 & 96 & 12.0 \\
\hline REM & 1.4 & 8.6 & 2.2 & 25 & 2.9 \\
\hline SWS & 1.3 & 0.0 & 0.0 & 0 & 5.4 \\
\hline \multicolumn{6}{|l|}{9} \\
\hline NREM 1 and 2 & 3.5 & 24.3 & 12.7 & 52 & 12.2 \\
\hline REM & 1.2 & 16.1 & 8.5 & 53 & 5.1 \\
\hline SWS & 1.9 & 2.0 & 1.0 & 50 & 3.7 \\
\hline \multicolumn{6}{|l|}{$10^{\#}$} \\
\hline NREM 1 and 2 & 4.1 & 33.0 & 28.5 & 86 & 33.1 \\
\hline REM & 0.8 & 30.5 & 21.9 & 72 & 11.0 \\
\hline SWS & 1.2 & 0.0 & 0.0 & 0 & 3.3 \\
\hline \multicolumn{6}{|l|}{11} \\
\hline NREM 1 and 2 & 5.4 & 50.1 & 47.3 & 94 & 4.4 \\
\hline REM & 0.8 & 15.0 & 13.7 & 91 & 6.3 \\
\hline SWS & 0.07 & 57.1 & 28.5 & 50 & 0.0 \\
\hline \multicolumn{6}{|l|}{$12^{\#}$} \\
\hline NREM 1 and 2 & 3.4 & 45.3 & 43.9 & 97 & 11.7 \\
\hline REM & 1.5 & 0.0 & 0.0 & 0 & 9.3 \\
\hline SWS & 1.1 & 0.0 & 0.0 & 0 & 4.5 \\
\hline \multicolumn{6}{|l|}{13} \\
\hline NREM 1 and 2 & 3.7 & 55.8 & 25.5 & 45 & 13.8 \\
\hline REM & 1.0 & 41.8 & 20.4 & 48 & 3.1 \\
\hline SWS & 1.7 & 27.4 & 2.4 & 9 & 3.6 \\
\hline \multicolumn{6}{|l|}{14} \\
\hline NREM 1 and 2 & 4.5 & 40.6 & 36.2 & 89 & 13.0 \\
\hline REM & 1.5 & 2.7 & 0.7 & 25 & 2.7 \\
\hline SWS & 0.9 & 12.5 & 4.5 & 36 & 13.6 \\
\hline \multicolumn{6}{|l|}{15} \\
\hline NREM 1 and 2 & 3.4 & 25.7 & 20.7 & 80 & 20.4 \\
\hline REM & 1.2 & 27.1 & 15.2 & 56 & 5.1 \\
\hline SWS & 2.0 & 0.5 & 0.0 & 0 & 4.5 \\
\hline
\end{tabular}

RAI: respiratory arousal index; RE: respiratory events; SAI: spontaneous arousal index; NREM: nonrapid eye movement; REM: rapid eye movement; SWS: slow wave sleep. "\#: seven patients excluded from analysis of variance across the three sleep states, as their AHI in REM and/or SWS was zero. 
Apnoealhypopnoea index, respiratory arousal index, spontaneous arousal index and sleep states

AHI differed significantly between sleep stages across the 15 patients $(\mathrm{p}<0.001)$. Pairwise comparisons showed significantly higher AHI during NREM 1 and 2 compared to SWS $(\mathrm{p}<0.001)$ and to REM sleep $(p=0.001)$, but no significant differences between REM and SWS ( $\mathrm{p}=0.4)$.

ANOVA, with the percentage of arousal-inducing apnoeas/hypopnoeas in the three sleep states being the within-subject variable, was performed between patients whose AHI was greater than zero in all three sleep states. Seven of the 15 patients were excluded as they failed to meet this criterion (table 3). All data from the remaining eight patients including all 610 apnoeas/ hypopnoeas showed significant, sleep stage-related differences in arousal induction $(\mathrm{F}=7.0, \mathrm{p}=0.005)$. Pairwise comparison showed a lower percentage of arousal-inducing apnoeas/hypopnoeas during SWS compared to NREM 1 and $2(p=0.001)$ and REM $(\mathrm{p}=0.02)$. There was no significant difference between NREM 1 and 2 and REM ( $\mathrm{p}=0.2$ ) (fig. 3).

The SAI differed significantly between the three sleep-states, across the 15 patients $(\mathrm{F}=14.9, \mathrm{p}<0.001)$. Pairwise comparison showed significant differences between NREM 1 and 2 and SWS $(\mathrm{p}<0.001)$, NREM 1 and 2 and REM $(\mathrm{p}<0.001)$, but not between SWS and REM $(\mathrm{p}=0.7)$.

\section{Apnoeas versus hypopnoeas}

Of all the 2,667 respiratory events, 1,430 were hypopnoeas and 1,237 were apnoeas. During NREM 1 and $253 \%$ were hypopnoeas, during SWS $88 \%$ and during REM sleep $43 \%$. Seventy-five per cent of hypopnoeas and $80 \%$ of apnoeas induced arousals. Chi-squared testing showed no significant difference

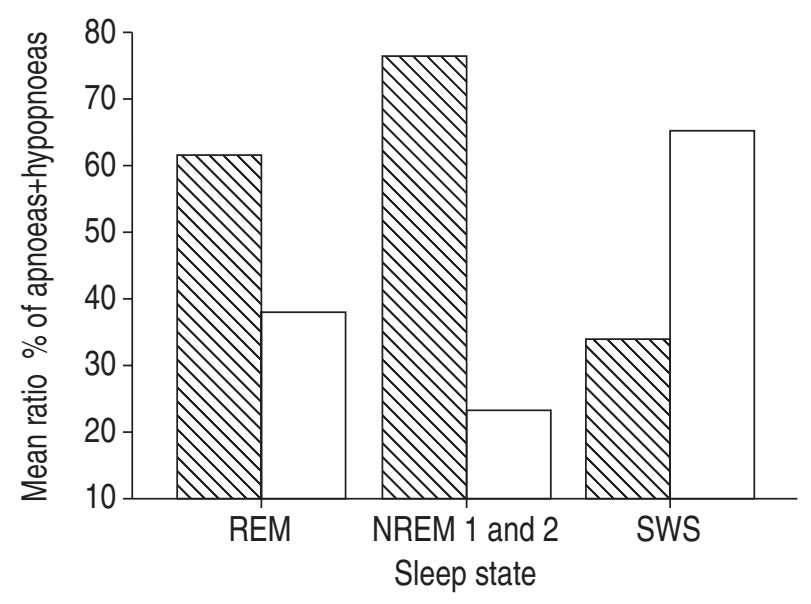

Fig. 3.-Comparison of arousal-inducing apnoeas/hypopnoeas during slow wave sleep (SWS), rapid eye movement (REM) and nonrapid eye movement (NREM) 1 and 2 sleep. $\mathbb{\$}$ : \% respiratory events with arousal; $\square$ : \% respiratory events without arousal. Per hour, REM: $62 \pm 8 \%$ apopnoeas/hypopnoeas caused arousals; NREM: $77 \pm 6 \%$ caused arousals; SWS: $34 \pm 8 \%$ caused arousals across $n=8$ patients.
Table 4.-Absence of association between respiratory event type and arousal induction ${ }^{\#}$

\begin{tabular}{lccc}
\hline & Apnoeas & Hypopnoeas & p-value \\
\hline $\begin{array}{l}\text { NREM 1 and 2 } \\
\text { Arousals }\end{array}$ & & & \\
$\quad$ Yes & 911 & 989 & 0.1 \\
$\quad$ No & 189 & 237 & \\
SWS & & & \\
Arousals & 5 & 26 & 0.7 \\
$\quad$ Yes & 10 & 87 & \\
$\quad$ No & & & \\
REM & & 54 & 0.8 \\
Arousals & 71 & 37 & \\
$\quad$ Yes & 51 & & \\
$\quad$ No & & & \\
\hline
\end{tabular}

NREM: nonrapid eye movement; SWS: slow wave sleep; REM: rapid eye movement. ${ }^{\#}$ : using the Chi-squared test; : two sided.

between the respiratory event type (apnoea or hypopnoea) in the arousal induction either overall or in any sleep-state across the patients $(\mathrm{p}>0.1)$ (table 4$)$.

\section{Apnoealhypopnoea duration, oxygen desaturation and} arousals

The median duration of arousal-inducing apnoeas/ hypopnoeas was $22.5 \mathrm{~s}$ (IQR $17-30 \mathrm{~s}$ ), the median duration of nonarousal-inducing apnoeas/hypopnoeas was $20 \mathrm{~s}$ (IQR 15.5-20 s). Median oxygen desaturation of arousal-inducing apnoeas/hypopnoeas was 5.0\% (IQR $0-7.0 \%$ ), and of nonarousal-inducing events was $5.0 \%$ (IQR $4.0-7.0 \%$ ). Across the 15 patients, comparisons of median duration and oxygen desaturation between arousal-inducing versus nonarousal-inducing apnoeas/hypopnoeas were not significant overall $(\mathrm{p}=0.8, \mathrm{p}=0.07)$ or during NREM 1 and $2(\mathrm{p}=0.9$, $\mathrm{p}=0.2$ ). In the eight patients in whom apnoeas/ hypopnoeas occurred in all three sleep-states, no significant differences were found in REM ( $\mathrm{p}=0.3$, $\mathrm{p}=0.6)$ or SWS $(\mathrm{p}=0.3, \mathrm{p}=0.2)$ (table 5).

\section{Time of the night}

Time of the night did not influence the cortical response to apnoeas/hypopnoeas across the 15 patients ( $p=0.2$ ) (fig. 4). Paired comparison between the mean RAI before and after 02:30 h during NREM 1 and 2, showed no significant changes across the 15 patients $(\mathrm{p}=0.6)$.

\section{Discussion}

This study has shown that apnoeas and hypopnoeas are less frequent in REM and SWS than light sleep. Arousals caused by apnoeas/hypopnoeas are less common from SWS, while spontaneous arousals are less common from SWS and REM than from light sleep. Furthermore, the cortical arousal response was 
Table 5.-Duration of hypopnoeas and apnoeas and oxygen desaturation

\begin{tabular}{lcccc}
\hline & All night & NREM 1 and 2 & REM & SWS \\
\hline $\begin{array}{l}\text { Duration s } \\
\text { Hypopnoeas }\end{array}$ & $21.8(20.0-27.5)$ & $21.5(20.0-26.5)$ & $37.0(26.1-41.5)^{\#}$ & $23.0(18.7-37.9)^{\#}$ \\
$\quad$ Apnoeas & $21.8(17.3-22.5)$ & $21.0(17.0-22.5)$ & $21.0(19.0-25.8)^{\#}$ & $20.3(18.0-33.1)^{\#}$ \\
Desauration $\mathrm{O}_{2} \%$ & $4.0(3.0-5.0)$ & $4.0(3.0-5.0)$ & $6.2(5.2-9.3)^{\#}$ & $4.5(2.2-7.7)^{\#}$ \\
$\quad$ Hypopnoeas & $5.0(4.0-6.0)$ & $5.0(4.0-6.0)$ & $5.0(3.0-9.0)^{\#}$ & $3.0(2.0-11.0)^{\#}$ \\
$\quad$ Apnoeas &
\end{tabular}

Data are presented as median (interquartile range). NREM: nonrapid eye movement; REM: rapid eye movement; SWS: slow wave sleep; $\mathrm{O}_{2}$ : oxygen. Results apply to $\mathrm{n}=15$ patients. ${ }^{\#}: \mathrm{n}=8$ subjects in whom apnoeas/hypopnoeas occurred in all three sleep states.

not influenced by the event type, duration, desaturation or time of occurrence during the night.

\section{Arousal threshold}

This study confirms the variability in the arousability of OSAHS patients in response to apnoeas/ hypopnoeas during SWS, compared to light and REM sleep. This is in agreement with the findings of BERRY et al. [14] who, based on measurements of respiratory effort, observed a cyclical increase in cortical arousalthreshold across the night, parallel to the increase of delta power.

The frequency of spontaneous arousals also changed significantly during SWS and REM sleep compared to light sleep, suggesting a higher arousal threshold during these sleep states. The difference between respiratory and spontaneous arousal frequencies during REM sleep might relate to the loss of muscle tone and the higher degree of upper airway instability [15]. This makes airway collapse more likely in REM sleep. Once started, the events tend to end with arousal often after long events, whereas spontaneous

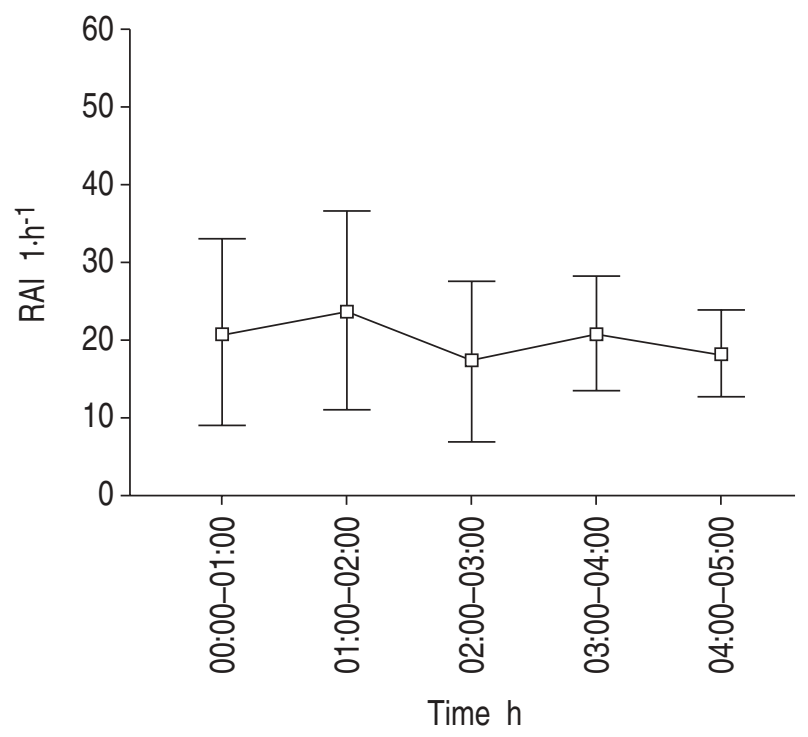

Fig. 4.-Hourly comparison of the respiratory arousal index (RAI) between 00:00 and 05:00 h showed no significant differences in apnoea/hypopnoea-related arousability during the night, across the 15 patients $(\mathrm{p}=0.2)$. arousals are less common in REM sleep. Furthermore, some "spontaneous" arousals may partly be linked to undetected, increased ventilatory effort $[14,16]$.

The current authors hypothesise that all afferent impulses reach the thalamic/hypothalamic region but onward transmission to the cortex is dependent on the sleep state. In SWS this transmission is inhibited, resulting in decreased detection of cortical arousals but maintenance of "nonvisible" autonomic arousals [17]. This hypothesis is supported by BRAUN et al. [18] who demonstrated changes in cerebral blood flow detected by positron emission tomography throughout the sleep-wake cycle, with selective deactivation of fronto-parietal areas and their functional disconnection to thalamic nuclei during SWS. Activity in primary and secondary sensory cortices was preserved for arousal from deep sleep in response to sudden threat. This finding suggests that the homeostatic drive for sleep, which cumulatively increases in sleep apnoeics as a result of repetitive arousing stimuli within and between nights [19], may be more prominent during SWS.

\section{Apnoeas versus hypopnoeas, arousals and apnoeal hypopnoea index}

The present study could not confirm the findings of STRADLING et al. [20] regarding the increased cortical response to apnoeas compared to hypopnoeas. This is in accordance with the current authors' clinical impression that patients with predominately apnoeic events are not sleepier than patients with predominately hypopnoeic events. STRADLING et al. [20] used a different hypopnoea definition, based on a $50 \%$ thermal airflow reduction but with no desaturation or visible arousal requirement. The latter study examined a mean of 18 apnoeas/hypopnoeas in 16 patients, albeit in carefully selected situations, in comparison to the mean of 178 events in 15 patients in the present study. The significant electroencephalographic differences at apnoea versus hypopnoea termination were not detected through the visual scoring which used a 3 s-threshold for arousal scoring, but through neural network analysis.

The sensitivity of the thermistor for the detection of hypopnoea may be questioned as it is a good qualitative but relatively poor quantitative sensor of airflow changes [21]. However, it is widely used. To avoid hypopnoea over-scoring, arousal and/or $\geqslant 3 \%$ 
oxygen desaturation were added to the 50\% amplitude reduction requirement, as recommended by the American Academy of Sleep Medicine [13]. The ratio of arousal-inducing hypopnoeas found in the present study is similar to that found by Gould et al. [21] although the method of hypopnoea detection and the scoring criteria differed. It is therefore possible, but unlikely, that the presently used hypopnoea definition has contributed to the lack of difference between apnoeas and hypopnoeas in inducing arousals.

The ratio of apnoeas to hypopnoeas varied with sleep stage, the ratio varying broadly in line with the AHI in that sleep stage. In SWS both the AHI and ratio of apnoeas to hypopnoeas were lowest. Both presumably reflect a greater relative stability of the upper airway in SWS compared with the other sleep stages. Given that there was no difference between arousal frequency following apnoeas compared with hypopnoeas overall, nor in any sleep stage, it is unlikely that the difference in arousal frequency in SWS resulted from this difference in event type.

The AHI decreased significantly from light to REM to SWS in the present study. Previous reports showed higher AHI during REM compared to NREM sleep [22]. This difference to the present outcomes maybe due to: 1) previous comparisons of REM against NREM stages 1-4, and/or 2) the fact that the presently studied group spent significantly more time in NREM 1 and 2 and 2,326 of the 2,667 apnoeas + hypopnoeas occurred during this state.

\section{Event duration, oxygen saturation and time of the night}

The significance of apnoea/hypopnoea duration and level of oxygen desaturation on the arousal induction was not consistent across the 15 patients.

The nonsignificant relation to oxygen desaturation may be due to: 1) poor accuracy of the method to reflect chemoreceptor activation, and/or 2) its nonsignificance in arousal induction, as previously suggested [23]. Hence, oximetry alone cannot reflect the extent of sleep fragmentation, suggesting that it is not a good diagnostic tool.

The lack of association between apnoea/hypopnoea duration and arousal induction is in accordance with previous observations of lengthening of apnoea across the night [24], as it implies that the more sleep is disrupted, the higher the arousal threshold becomes and the less important apnoea/hypopnoea duration becomes in inducing arousal, which is the case in the patient group studied.

The present study could not confirm the findings of a modelling study regarding the progressive increase in arousal threshold across the night [7]. The current findings are in keeping with the findings of REEs et al. [9] and they may be due to the disturbed sleep cycle and the within and between nights sleep deprivation in sleep apnoea patients, whose circadian rhythm and the homeostatic sleep dynamics are disturbed. The result is a high arousal threshold at sleep onset in this group of patients.

\section{Study limitations}

Limitations of this study include power, definitions and multiple comparisons. Fifteen patients were studied, but seven of these were excluded post hoc from the across sleep-states comparisons as they had no events in a sleep stage, usually in SWS and for three patients in REM sleep. Therefore, it can be questioned whether these data are applicable to all OSAHS patients. The findings between the eight studied patients are consistent in regard to the low ratio of arousal-inducing apnoeas/hypopnoeas during SWS, which varied between $0-66 \%$ (table 3 ).

The patients were randomly selected and the group studied included mild, moderate and severe sleep apnoeics with symptoms and polysomnographic findings typical of the syndrome. The low percentage of REM and SWS is common in untreated OSAHS patients and is an indicator of treatment success and compliance [25].

All the recorded apnoeas/hypopnoeas were studied. This represents a large body of data with which to answer the questions posed. The current results are not only robust, but represent the largest body of events which have been similarly analysed. Therefore, the study is adequately powered to detect clinically important differences.

There are many definitions of hypopnoea and arousal used in the literature. The hypopnoea definition used here fulfils the ASDA recommendations [13]. The inclusion of arousals or desaturation in the definition may lead to a greater association with arousals than would be found using other ASDA accepted definitions, i.e. based on thoraco-abdominal movement or nasal pressure alone. The arousal definition used, has been used in previous studies and validated against respiratory events and outcomes [9].

The current authors tried to keep the number of comparisons to a minimum and the study defined primary end points clearly. However, the present study involved 17 statistical comparisons which would bias the study to show significant differences, whereas the current results are largely negative, including the a priori hypotheses that event type, duration, desaturation and time of the night would predispose to arousal induction.

The current authors acknowledge that the present study did not assess all factors which may influence the cortical response to apnoeas/hypopnoeas. These include changes in upper airway resistance, snoring and body posture. STRADLING et al. [20] have shown that the latter is not a significant contributor to cortical changes, as detected through neural networks. However, analysis of these factors in the present study was not planned and is not possible retrospectively from the data collected.

Despite the modification in the time threshold used to score arousals, $20 \%$ of respiratory events were not terminated by cortical arousals in the present study. This suggests that lack of detection of cortical changes at apnoea/hypopnoea termination is not due to the arousal definitions used but is related to sleep/wake physiology, the processes of which can not be detected through the standard techniques. 
It is unclear what terminates apnoeas/hypopnoeas which are not terminated by visible cortical arousals. One possible explanation is that a different type of reaction, the autonomic, terminates apnoeas/hypopnoeas at thalamus/hypothalamus level, linked to presso-/mechano-/chemo-receptor afferent stimuli [8, 16]. Autonomic reactions are not represented at the cortex, possibly due to the higher cortical arousal threshold, which during SWS is linked to the synchronised appearance of delta waves. Alternatively, such autonomic arousals may be represented at the cortex but the changes cannot be detected with standard techniques and/or topology.

Monitoring of frontal brain activity as well as autonomic activity and/or the application of neural networks or Fast Fourier Transform analysis might improve the detection of changes at apnoea/hypopnoea termination and thus minimise the difference between apnoea/hypopnoea index and respiratory arousal index. There is some evidence in support of this contention $[20,26,27,28]$. Whether differences between sleep stages would then be requires further study.

\footnotetext{
Acknowledgements. The authors would like to thank N. McArdle, P. Wraith and $\mathrm{H}$. Engleman for their helpful comments, E. Dolan for her secretarial assistance.
}

\section{References}

1. Young T, Palta M, Dempsey J, Skatrud J, Weber S, Badar S. The occurrence of sleep-disordered breathing among middle-aged adults. N Engl J Med 1993; 328: $1230-1235$.

2. Teran-Santos J, Jiménez-Gómez A, Cordero-Guevara J. Co-operative Group Burgos-Santander. The association between sleep apnea and the risk of traffic accidents. N Engl J Med 1999; 340: 847-851.

3. Young T, Blustein J, Finn L, Palta M. Sleepdisordered breathing and motor vehicle accidents in a population-based sample of employed adults. Sleep 1997; 20: 608-613.

4. Kingshott RN, Engleman HM, Deary IJ, Douglas NJ. Does arousal frequency predict daytime function? Eur Respir J 1998; 12: 1264-1270.

5. Bennett LS, Barbour C, Langford B, Stradling JR, Davies RJ. Health status in obstructive sleep apnea: relationship with sleep fragmentation and daytime sleepiness, and effects of CPAP treatment. Am J Respir Crit Care Med 1999; 159: 1884-1890.

6. Martin SE, Engleman HM, Deary IJ, Douglas NJ. The effect of sleep fragmentation on daytime function. Am J Respir Crit Care Med 1996; 153: 1328-1332.

7. Roehrs T, Merlotti L, Petrucelli N, Stepanski E, Roth T. Experimental sleep fragmentation. Sleep 1994; 17 : 438-443.

8. Martin SE, Wraith PK, Deary IJ, Douglas NJ. The effect of non-visible sleep fragmentation on daytime function. Am J Respir Crit Care Med 1997; 155: 1596-1601.

9. Rees K, Spence DP, Earis JE, Carverley PM. Arousal responses from apnoeic events during NREM sleep. Am J Respir Crit Care Med 1995; 152: 1016-1021.

10. Whyte KF, Allen MB, Jeffrey A, Gould GA, Douglas NJ. Clinical features of the sleep apnoea/hypopnoea syndrome. $Q J \mathrm{Med}$ 1989; 72: 659-666.
11. Rechtschaffen A, Kales A. A manual of standardised terminology: techniques and scoring systems for sleep stages of human subjects. Publication No: 204. Washington, DC, National Institutes of Health, 1968.

12. ASDA Task Force Report. EEG Arousals: Scoring rules and examples. Sleep 1992; 15: 173-184.

13. American Academy of Sleep Medicine Task Force Report. Sleep-related breathing disorders in adults: recommendations for syndrome definition and measurement techniques in clinical research. Sleep 1999; 22: 667-689.

14. Berry RB, Asyali MA, McNellis MI, Khoo MC. Within-night variation in respiratory effort preceding apnoea termination and EEG delta power in sleep apnoea. J Appl Physiol 1998; 85: 1434-1441.

15. Hudgel DW, Hendricks C. Palate and hypopharynx sites of inspiratory narrowing of the upper airway during sleep. Am Rev Respir Dis 1988; 138: 1542-1547.

16. Gleeson K, Zwillich CW, White DP. The influence of increasing ventilatory effort on arousal from sleep. $\mathrm{Am}$ Rev Respir Dis 1990; 142: 295-300.

17. Pitson D, Chhina N, Knijn S, Van Herwaaden M, Stradling J. Changes in pulse transit time and pulse rate as markers of arousal from sleep in normal subjects. Clin Science 1994; 87: 269-273.

18. Braun AR, Balkin TJ, Wesensten NJ, et al. Regional cerebral blood flow throughout the sleep-wake cycle; an $\mathrm{H}_{2}{ }^{15}$ O PET study. Brain 1997; 120: 1173-1197.

19. Chugh DK, Weaver TE, Dinges DF. Neurobehavioral consequences of arousals. Sleep 1996; 19: S198-S201.

20. Stradling JR, Pitson DJ, Bennett L, Barbour C, Davies RJ. Variation in the arousal pattern after obstructive events in obstructive sleep apnea. Am J Respir Crit Care Med 1999; 159: 130-136.

21. Gould GA, Whyte KF, Rhind GB, et al. The sleep hypopnea syndrome. Am Rev Respir Dis 1988; 137: 895-898.

22. Sackner MA, Lauda J, Forrest T, Greeneltch D. Periodic sleep apnea: chronic sleep deprivation related to intermittent upper airway obstruction and central nervous system disturbance. Chest 1975; 67: 164-171.

23. Gyulay S, Olson LG, Hensley MJ, King MT, MurreeAllen K, Saunders NA. A comparison of clinical assessment and home oximetry in the diagnosis of obstructive sleep apnea. Am Rev Respir Dis 1993; 147: $50-53$.

24. Montserrat JM, Kosmas EN, Cosio MG, Kimoff RJ. Mechanisms of apnea lengthening across the night in obstructive sleep apnea. Am J Respir Crit Care Med 1996; 154: 988-993.

25. McArdle N, Douglas NJ. Effect of continuous positive airway pressure on sleep architecture in the sleep apneahypopnea syndrome: a randomized controlled trial. Am J Respir Crit Care Med 2001; 164: 1459-1463.

26. Dingli K, Assimakopoulos T, Fietze I, Witt C, Douglas NJ. Neural Networks in the arousal detection in sleep apnea patients (abstract). Am J Respir Crit Care Med 2001; 163: A953.

27. Walsleben JA, O'Malley EB, Bonnet K, Norman RG, Rapoport DM. The utility of topographic EEG mapping in obstructive sleep apnea syndrome. Sleep 1993; 16: S76-S78.

28. O'Malley EB, Walsleben JA, Norman RG, Rapoport DM. Detection of unappreciated respiratory-related EEG arousals (abstract). Am J Respir Crit Care Med 1996; 153: A568. 